\title{
System Dynamics Modelling for Forest Fuelwood Management in India
}

Study Area: Sirsi (Karnataka) \& Mandla (Madhya Pradesh)

Kunal Bharat, Satvant Kaur Saini*, Karan Khosla, Swapan Mehra, N. Ravindra

Iora Ecological Solution Pvt. Ltd., 225/164B, Lado Sarai, New Delhi - 110030

Coordinates: $14.6195^{\circ} \mathrm{N} 74.8354^{\circ} \mathrm{E} \& 22.6^{\circ} \mathrm{N} 80.38^{\circ} \mathrm{E}$

Key words: Simulation, Social-Ecological Systems

\section{Abstract}

A new tool, the IFSDM (IEMaC Fuelwood System Dynamics Model), uses system dynamics modelling and simulation to help understand the causal relationships between forest fuelwood availability, regeneration and various kind of extractions to estimate over time how assisted and natural regeneration of the biomass compares to extraction practices for local and distributed needs. It is intended to act as a decision support system for fuelwood management which will assess sustainable fuelwood harvesting levels as well as scientif ically identify and examine investment opportunities and policies to reduce fuelwood pressure on forest.

\section{Introduction:}

In India, nearly 275 million people depend on forests for their sustenance (World Bank, 2006) with 170 ,ooo villages located in or near forests out of total 641,00o villages (MoEF, 2006; Census of India, 2011). Even though energy consumption patterns in India have been witnessing a change over the past few decades, traditional biomass based fuels such as fuelwood still remain as vital as before. This is particularly true for rural India where over 77 percent of the households depend on fuelwood for cooking and heating (NSSO, 2008).

Apart from fuelwood, forests provide numerous other essential ecosystem goods and services important at local and global level. These range from tangibles such as medicinal plants, timber and non-timber forest products to life-supporting regulatory services like watershed services, carbon storage and habitat for wildlife as well as cultural services such as recreation, aesthetic values and spiritual benef its.

However, the provision of ecosystem goods and services directly depends on the health of the forest resources (Benayas et al., 2009). Negative environmental and socio-economic

*Corresponding Author: satvant@ioraecological.com 
impact arises when the rate of extraction of resources, such as fuelwood and small timber, exceed the rate of natural regeneration coupled with inefficient energy conversion technologies.

In India, although the overall forest cover has remained stable over the past twenty years, approximately $40 \%$ of the forests are showing a trend of degradation (Aggarwal et al., 2009; Bahuguna et al., 2004). Majority of this can be attributed to unsustainable extraction and population pressure. Hence, the issue in focus here is unsustainable extraction of fuelwood from natural forests and use of ineff icient energy conversion technologies.

Over the past 3 decade, tremendous amount of investments have been made to reduce the fuelwood pressure on natural forests. For example in India, first, the National Program on Improved Cook stoves (NPIC, 1983; 2002) and now the National Biomass Cook stoves Initiate (NBCI) since 2009. But these and many others have created limited difference which does not justify the spent amount (Winrock, 2004; IIT \& TERI, 2010; Lambe, 2012). This could be attributed to incomplete and inadequate understanding of the current scenario. There is an urgent need for rationally identified investments aimed at reducing fuelwood pressure on forests which are based on holistic and scientific understanding of the situation. This is where system dynamics comes in.

\section{System Dynamics:}

"System dynamics is a methodology for studying and managing complex systems which changes over time." -Andrew Ford (System

Dynamics Models of Environment, Energy and Climate Change)

System dynamics is a perspective and set of computational tools that help in understanding the structure and dynamics of complex systems. System dynamics modelling enables one to build computer simulations of these complex systems to be used for policy analysis and design. It deals with stocks, flows, feedback loops and time delays that affect the entire system. It has the capability to provide extremely useful insight by promoting interdisciplinary understanding of complex systems.

System dynamics modeling has been used for various environmental applications such as land use, ground water management, urban water systems, wildlife population and habitat, climate change, etc. (Van Delden et al., 2007; Lauf et al., 2012; Elsawah et al., 2012; Ford, 2014). In the forestry sector, system dynamics modelling can be used to understand the dynamic nature of forest ecosystem, the end users of a forest resource and the relationship between them. However, there are only a few past examples of system dynamics modelling being used in relation to forest resource and its utilization.

A case study from Indonesia (Purnomo et al., 2011) utilizes system dynamics modeling, focusing adequately on social and biophysical factors, for evaluating collaborative forest management policies. A study in India (Yadama et al., 2010) used Community Driven System Dynamics to "test the effects of forest protection committees and the National Rural Employment Guarantee Scheme on livelihoods and forests" for a small community in Chittoor district in Andhra Pradesh. This extremely micro-level study (64 households) 
focuses on socio-economic factors and has very simplified modelling for the biophysical side. WISDOM, a GIS based tool integrates dispersed data, from direct and indirect sources, on fuelwood supply and demand to identify "hot spots" (Drigo et al., 2002; Ghilardi et al., 2009). However, this is more of a GIS tool showing multi-scalar demand and supply balance estimates and does not use system dynamics modelling. It does not describe the changes over timeand scope for simulations for policy analysis is missing.

\section{IEMaC Fuelwood System Dynamics Model (IFSDM):}

Innovations in Ecosystem Management and Conservation (IEMaC) is a project initiated and approved by USAID under the Innovations in Forest Resource Management (InFoRM) Program. The project aims to reduce pressure on forests by developing innovative gender sensitive models for improved fuelwood management, community-centric NTFP value chains and community based forest monitoring tools. Iora Ecological Solutions is leading this project with Bioversity International and MART as partner organizations in this project.

One of the ways through which the project aims to reduce pressure on forests is by developing an IEMaC Fuelwood System Dynamics Model (IFSDM). The IFSDM builds causal relationships between fuelwood availability, regeneration and various kinds of extraction to estimate, over time, how assisted and natural regeneration of the biomass compares to extraction practices for local and distributed needs, thereby providing a base tool for assessment of sustainable harvesting levels. It is intended to act as a decision support system for fuelwood management which will scientifically identify and examine investment opportunities and policies to reduce fuelwood pressure on forest. Such a tool could be ideal for policy evaluation and impact assessment, as it can capture multiple disciplines related to forest management.

\section{How will it do so?}

1. Understand, quantify and visualize the current scenario of fuelwood resource use by studying the supply (ecological) and demand (users) side i.e. stock, regeneration, extraction quantity, extraction techniques, end users demand and socio-economic factors influencing that demand.

2. Model the causal relationships between different components.

3. Understand the sustainability of the current scenario by simulating the future forest stock under current consumption patterns and identify priority intervention areas.

4. Identifying multiple investment opportunities or policies to reduce pressure at priorityareas. The impact of each of these investments or policies can beanalyzed by running simulations and the most feasible can be adopted on ground.

The beauty of the model lies in the fact that it takes a systems approach whileassisting in taking decisions. All the significant components of the system (relevant to the purpose of the model) and the dynamics between them have been tried to take into account. Such an approach would tremendously increase the chances of an investment or policy being successful as it is based on a holistic and scientif ic understanding of the pressure created by 
fuelwood demand on forests. It deviates from an approach where only select aspects of a problem are studied prior to planning investments. Studying only select aspects of a problem limits us as we cannot anticipate the effect of other factors, which could be extremely signif icant given the interconnected nature of things in the present world.

The IFSDM will help scientifically and rationally guide investments and policies to tackle the problem of pressure created by fuelwood demand on forest. Key impacts at the project sites will be:

1. Improving forest biomass, carbon stocksand biodiversity.

2. Improvement in energy access through identification and deployment of viable technology options at household and commercial level.

3. Other co-benefits such as health and socio-economic improvement through deployment of alternative clean technology and improvement in felling regime.

\section{StudyArea}

Presently, the IFSDM is being developed for and based on the two project landscapes of the IEMaC project i.e. Sirsi (Karnataka) and Mandla (Madhya Pradesh). It is being developed in a manner that will allow it to be replicated for other sites in India as well.

The sites are representative of major forest types of India. The predominant forest type in Mandla is dry deciduous mixed and teak forests and Sirsi has a mix of evergreen, semi evergreen, moist deciduous and dry deciduous forests. The sites have a significant forest dwelling tribal population with high dependence on the surrounding forest. Fuelwood is an essential sustenance forest product for the people in the study area. Future of this resource is threatened due to unplanned, poor or destructive extraction techniques and lack of knowledge regarding thealternative sustainable practices or technology.

The model is being developed on Stella Professional, a model building and simulation software developed by isee systems. Many field activities such as key informant interviews, ecological and socio-economic assessment have been undertaken at the IEMaC project sites as part of the IFSDM development process. The development is being peer-reviewed through periodic Round Tables and model validation with a multi-disciplinary panel of expertsa part of the IFSDM Advisory Committee.

\section{Structure of the IFSDM:}

The structure of the model as per IEMaC project sites, Mandla and Sirsi, is shown in figure 1. The two core systems of the IFSDM are the forest resource system and the end user system. Within both these systems are sub-systems. There are dynamics at work within systems and sub-systems as well as between systems and sub-systems. All these systems, sub-systems and their dynamics together make the cohesive bigger system. Certain parameters being built into the model are generic and hold good for both Mandla and Sirsi, however, some are site specif ic.

Supply side-Forest resource system

A fully functioning and reasonably accurate forest stand system being built into the model keeps track of biomass as trees age and growth and helps assess more realistically the 
impact of extraction practices. The forest stand system has been classif ied into 4 stages, as per diameter, which forms the tree growth stages (table 1). The biomass in trees grows over time based on parameters fed into the model. There are inflows and outflows in each stage (table1).

Ecological assessment through field sample plots in the forests is used to assess current stock of biomass along with regeneration status and data from the State Forest Departments, local academic/scientif ic experts and review of scientific literature helps estimate the growth rates of this biomass stock in different stages. For future replication of IFSDM at other sites, field ecological assessment can be substituted with pre-existing ecological data present with the Forest Department.

Table 1: Tree growth stages

\begin{tabular}{|c|c|c|c|c|}
\hline $\begin{array}{l}\text { Tree Growth } \\
\text { Stage }\end{array}$ & $\begin{array}{l}\text { Regenerating } \\
\text { seedlings (I) }\end{array}$ & $\begin{array}{l}\text { Regenerating sapling } \\
\text { biomass (II) }\end{array}$ & $\begin{array}{l}\text { Young biomass } \\
\text { (III) }\end{array}$ & $\begin{array}{l}\text { Mature biomass } \\
\text { (IV) }\end{array}$ \\
\hline Diameter & NA & $2-10 \mathrm{cmdbh}$ & $10-20 \mathrm{~cm} \mathrm{dbh}$ & $>20 \mathrm{cmdbh}$ \\
\hline Inflow & $\begin{array}{l}\text { Natural regeneration/ } \\
\text { recruitment, ANR \& } \\
\text { new plantations }\end{array}$ & $\begin{array}{l}\text { New plantations } \\
\text { seedlings maturing }\end{array}$ & Saplings maturing & $\begin{array}{l}\text { Young biomass } \\
\text { maturing }\end{array}$ \\
\hline Outflow & $\begin{array}{l}\text { Maturity to sapling, } \\
\text { grazing, trampling, } \\
\text { fire, mortality, etc. }\end{array}$ & $\begin{array}{l}\text { Maturity toyoung } \\
\text { biomass, grazing, fire, } \\
\text { trampling, mortality, } \\
\text { etc. }\end{array}$ & $\begin{array}{l}\text { Maturity to mature biomass, } \\
\text { extraction for poles, small } \\
\text { timber, mortality,fuelwood, } \\
\text { F.D. inter-culture } \\
\text { operations etc. }\end{array}$ & $\begin{array}{l}\text { Extraction for } \\
\text { poles, fuelwood, } \\
\text { small timber, } \\
\text { timber, mortality, } \\
\text { etc. }\end{array}$ \\
\hline
\end{tabular}

Demand side-User system

The "demand" side of the model estimates quantity, technique and purpose of biomass extraction across various levels in the region. Socio-economic assessment is taken up to assess major drivers of fuel wood extraction, quantum of extraction and their behavior. Techniques including focus group discussion, key informant interviews and household survey are utilized. Though drivers of extraction vary in both States (Madhya Pradesh and Karnataka), in general they can be split into two categories: consumption for domestic use and commercial use. Each of these users is a sub-system on their own with internal dynamics. Various socio-economic factors such as

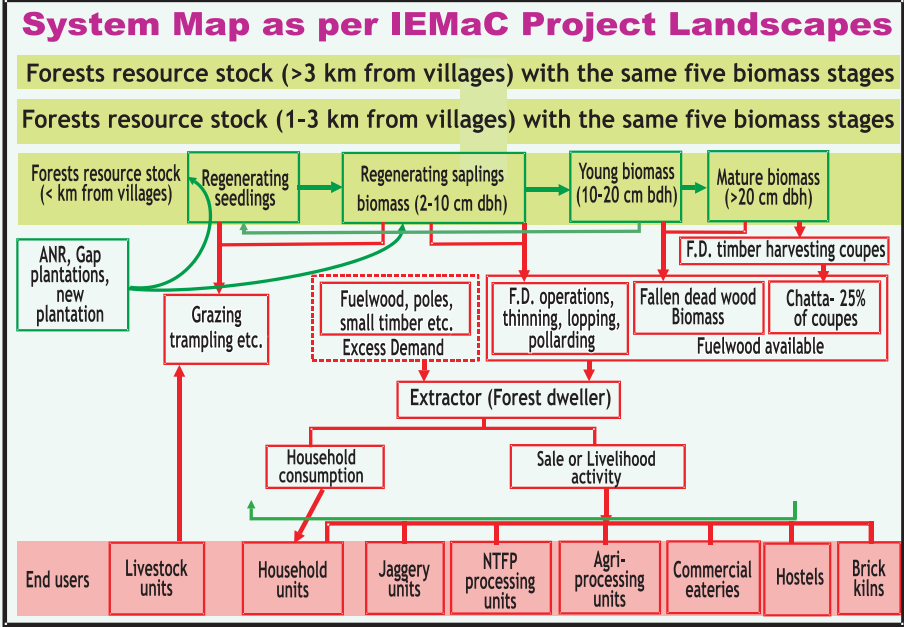

Figure 1: IFSDM structure 
population, income, price of fuelwood, etc. influence the behavior of the users or subsystems. A very important factor to consider is the user system, especially since this model revolves around fuelwood use, is energy conversion technology. This greatly influences quantity of fuelwood being extracted.

Modelling supply side and demand side over time:

Once the supply and demand side variables and parameters are in place, model is run and future forest stock simulated over time to understand the sustainability of the current scenario given current consumption patterns. This will also highlight priority intervention areas. Next step is identifying multiple investment opportunities or policies to reduce pressure at priority areas and the impact of each of these can be analyzed by running simulations on the

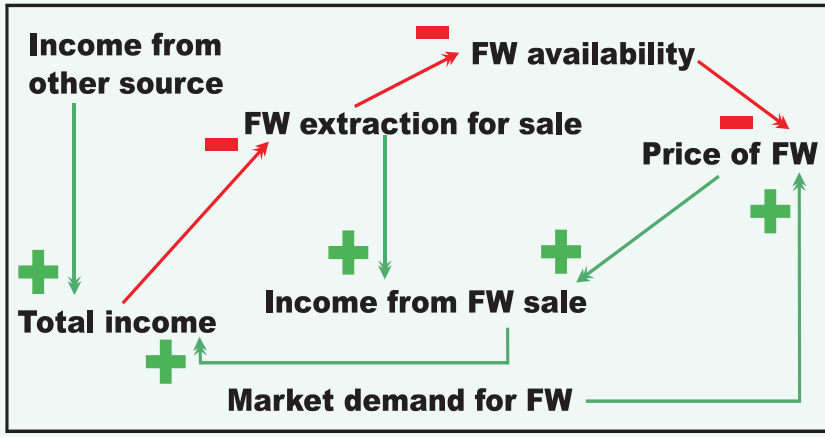

Figure 2: Feedback loop showing relationship among household income, fuelwood (FW) extraction, price, availability and demand. software.

The model is being designed keeping in mind multiple stakeholders. The Forest Departments, however, are one of the key stakeholders. The IFSDM is intended be a decision support tool to be used by the Forest Departments in India for optimal budget utilization, scientif ic planning and improved fuelwood harvesting practices. It will also be of interest to international donor agencies with projects related to fuelwood and clean technology, clean technology companies and government bodies such as Ministry of New and Renewable Energy (MNRE), National Institution forTransforming India (NITI) Aayog and Ministry of Rural Development.

Apart from giving a thorough understanding of the entire fuelwood consumption system (users, sources, sustainability over time, etc.) of a landscape, will also enable one to demonstrate the impact of introducing better and efficient technologies by running simulations and showing alternative scenarios over time with corresponding social and environmental benefits. Besides having great use in policy and investment decision making it, such a tool is also very useful for information dissemination and awareness.

Acknowledgements:

This research is supported by USAID. We thank the members of the IFSDM Advisory Committee and the key informants for theirvaluable insight and expertise.

\section{References:}

Aggarwal, A., Paul, V. \& Das, S. (2009): Forest Resources: Degradation, Livelihoods, and Climate Change. In: Datt D. et al. (eds.) Looking Back to Change Track. New Delhi:TERI. p.91-108.

Datt, D. \& Nischal, S. (2009): Looking Back to Change Track. New Delhi:TERI.p.219. 
Bahuguna, V.K., Mitra, K., Capistrano, D. \& Saigal, S. (2004): Root to Canopy: Regenerating Forests through Community State Partnerships. New Delhi: Winrock International India / Commonwealth Forestry Association India Chapter. p.309-316.

Benayas Rey, J.M., Newton, A.C., Diaz, A. \& Bullock, J.M. (2009): Enhancement of Biodiversity and Ecosystem Services by Ecological Restoration:A Meta-Analysis. Science. 28 (325):1121-1124.

Drigo, R., Masera, O.R. \& Trossero, M.A. (2002): Woodfuel integrated supply/demand overview mapping WISDOM:A geographical representation of woodfuel priority areas. Unasylva. 53 (211):36-40.

ElSawah, S., Haase, D., Delden, H. Van, Pierce, S., ElMahdi A., Voinov, A.A. \& Jakeman, A.J. (2012): Using system dynamics for environmental modelling: Lessons learnt from six case studies. In R. Seppelt, A.A. Voinov, S. Lange, D. Bankamp (eds.) Proceedings of the sixth biennial meeting of the International Environmental Modelling and Software Society. Leipzig, Germany: International Environmental Modelling and Software Society (iEMSs).p.1367-1374.

(*http://www.iemss.org/sites/iemss2012//proceedings/D4_1362_ElSawah_et_al.pdf)

Ford, A. (2014): System Dynamics Models of Environment, Energy and Climate Change. Encyclopedia of Complexity and Systems Science. p.782-801.

Ghilardi, A., Guerrero, G., \& Masera, O. (2009): A GIS-based methodology for highlighting fuelwood supply/demand imbalances at the local level:A case study for Central Mexico. Biomass Bioenerg., 33(67):957-972.

IIT \& TERI (2010): New Initiative for Development and Deployment of Improved Cookstoves: Recommended Action Plan: Final Report, prepared for the Ministry of New and Renewable Energy, Government of I n d i a , $\quad \mathrm{N}$ e w D e $1 \mathrm{~h}$ i . (*http://www.indiaenvironmentportal.org.in/files/Final_Report_Cookstove.doc)

. p . 3 .

Lambe, F. \& Atteridge, A. (2012): Putting the Cook Before the Stove: A User-Centered Approach to Understanding Household Energy Decision-Making, in Working Paper 2012 (03) of the Stockholm Environment Institute(SEI).p.7.

Lauf, S., Haase, D., Hostert, P., Lakes, T. \& Kleinschmit, B. (2012): Uncovering land-use dynamics driven by human decision-making A combined model approach using cellular automata and system dynamics. Environ. Model. Softw. 2:71-82.

Ministry of Environment and Forests (2006): Report of the National Forest Commission. New Delhi: Ministry of Environment and Forests, Government of India. p.421.

National Sample Survey Organisation (NSSO) (2007-08): Energy used by Indian households. Report No. 530. New Delhi: National Sample Survey Organisation, Department of Statistics.

Purnomo, H., \& Mendoza, G. (2011): A system dynamics model for evaluating collaborative forest management: a case study in Indonesia. Int. J. Sust. Dev. World Eco., 18(2):164-176.

Van Delden, H., Luja, V. and Engelen, G. (2007) Integration of multi-scale dynamic spatial models of socioeconomic. Environ. Model. Softw.,22:223-238.

Winrock International (2004): Household Energy, Indoor Air Pollution and Health: Over of Experiences and Lesson in India, prepared for the United States Environmental Protection Agency, USA.

World Bank (2006): India: Unlocking Opportunities for Forest Dependent People in India. Report No. 34481 IN, World Bank: South Asia Region. p.85.

Yadama, G.N., Hovmand, P.S., FES \& Chalise, N. (2010): Community Driven Modelling of Social-Ecological Systems: Lessons from Andhra Pradesh, India. 28th International Conference of the System Dynamics Society, p. 92. ( ${ }^{*}$ http://www.systemdynamics.org/conferences/2010/proceed/proceed.pdf)

${ }^{*}$ Accessed on 15/10/2015 